\title{
Antimicrobial Activity of Two Antitumour Agents and Ribonucleotide Reductase Inhibitors, Pyridine-2-carboxaldehyde Thiosemicarbazone and the Acetate Form of its Copper(II) Chelate
}

\author{
Hannu Elo \\ Division of Pharmaceutical Biology, Faculty of Pharmacy, P. O. Box 56 (Viikinkaari 5, \\ Biocenter 2), FIN-00014 University of Helsinki, Finland. Fax: +358-9-19159882. \\ E-mail: Hannu.Elo@Helsinki.Fi
}

Z. Naturforsch. 62 c, 498-506 (2007); received January 31/March 8, 2007

\begin{abstract}
Some copper chelates have potent antitumour activity, and in some cases also the free ligands have activity in vivo. Yet, little is known about their antimicrobial properties. Copper(II) chelates of the thiosemicarbazones of $\alpha$ - $N$-heterocyclic carboxaldehydes constitute one important group of such agents, also their ligands having marked antitumour activity. Both the ligands and chelates inhibit ribonucleotide reductase. Some ligands have been or are under clinical trials as antineoplastic agents. I report here a study on the antimicrobial properties of the prototype compounds of this group, pyridine-2-carboxaldehyde thiosemicarbazone and its copper(II) chelate. They were tested against nine microbes, including bacteria (Bacillus cereus, Escherichia coli, Pseudomonas aeruginosa, Staphylococcus aureus, Staphylococcus epidermidis and Streptococcus lactis), yeasts (Candida albicans and Saccharomyces cerevisiae) and one mold (Aspergillus niger). Two clinical isolates of Bacillus sp. and one reference strain were also studied. Both the ligand and the chelate had marked activity. The ligand displayed considerable activity against all bacteria except for S. lactis, and its activity against $E$. coli and $P$. aeruginosa was that high that practical applications might be considued. It was highly active against $A$. niger and moderately active against $C$. albicans. The chelate was highly active against $S$. epidermidis and $S$. cerevisiae. Both compounds inhibited the clinical isolates markedly. Since some related ligands have been or are in clinical trials on humans or are entering them, their route to clinical use, also as antimicrobials, might be much more straightforward than that of substances, whose toxicity in humans is wholly unexplored.
\end{abstract}

Key words: Antibacterial Agents, Antifungal Agents, Antimicrobial Metal Complex

\section{Introduction}

Some copper chelates have highly potent antitumour activity both in vitro and in vivo. These compounds include trans-bis(salicylaldoximato)copper(II) and its analogues (Elo and Lumme, 1985, 1986, 1987; Elo et al., 1987; Elo, 1987a, b, 2004a; Elo and Sunila, 1987) as well as the copper(II) complexes of kethoxal bis(thiosemicarbazone) and of some analogues thereof (Petering, 1980; Agrawal and Sartorelli, 1975). One further group of cytotoxic copper(II) chelates is constituted by the 1:1 copper(II) complexes of the thiosemicarbazones of various $\alpha$-N-heterocyclic carboxaldehydes (Brockman et al., 1956; Petering, 1980; Antholine et al., 1976; Saryan et al., 1979). The 1:1 copper(II) chelate of pyridine-2-carboxaldehyde thiosemicarbazone is the most thoroughly studied congener amongst the last-mentioned group. Copper chelates belonging to any of the above- mentioned classes have a drastic cytotoxic action. Thus, for example, trans-bis(salicylaldoximato)copper(II) totally inhibits the proliferation of all human as well as murine tumour cell lines so far tested in a content as low as ca. 5 ppm, and the cytotoxic action is very rapid (Elo and Lumme, 1985, 1987; Elo, 2004a; unpublished observations).

In the case of salicylaldoximato chelates, only the copper chelate itself has antitumour activity, while even high concentrations of the free ligand are devoid of cytotoxicity in vitro (no in vivo studies have been performed on the antitumour properties of the ligand alone). Even high concentrations of free $\mathrm{Cu}^{2+}$ ions have a drastically lower activity than low concentrations of the chelates (Elo and Lumme, 1987). In the case of bis(thiosemicarbazone)s as well as in the case of thiosemicarbazones of $\alpha$-N-heterocyclic carboxaldehydes, also the free ligands have antitumour activity. Bis(thiosemicarbazone)s lose, however, 
their activity if the diet of tumour-bearing animals is made free of copper. In the case of thiosemicarbazones of $\alpha$ - $N$-heterocyclic carboxaldehydes, experiments in animals as well as clinical trials in humans have shown that the thiosemicarbazones mobilize large amounts of iron in the body which is excreted in urine. In vitro, the free ligands (the thiosemicarbazones of $\alpha-N$-heterocyclic carboxaldehydes) have no cytotoxicity, while their copper(II) complexes as well as the iron complexes of some ligands cause distruction of tumour cells (Petering, 1980). New clinical trials on ligands of this group have been started recently (Shao et al., 2006; Feun et al., 2002; Murren et al., 2003).

The cytotoxic and antitumour properties of the compounds described above suggest that the complexes or ligands (or both) might possibly have also antimicrobial properties. It would be theoretically interesting to know, whether cytotoxic copper chelates have also antibacterial or antifungal properties. Such properties might have important practical implications concerning the development of novel antimicrobial drugs. Yet, little appears to be known on the effects of these agents on microbes. There are one short report by the present author on the lack of antiviral properties against HIV of some copper salicylaldoximates (Elo, 2004b), a couple of papers describing the effects of one ligand, 1-formylisoquinoline thiosemicarbazone, on Escherichia coli B (Hochman et al., 1972a, b) and some papers in which the antibacterial activity of pyridine-2-carboxaldehyde thiosemicarbazone and one derivative thereof on E. coli is reported (Chattopadhyay et al., 1990; Maiti et al., 1988). The lack of antibacterial studies is even more surprising in the light of the well-known fact that cis-dichlorodiammineplatinum(II) (cisplatin), one of the clinically most important anticancer drugs ever used (Rosenberg, 1980), was originally discovered as a result of its peculiar effects on the bacterium $E$. coli (Rosenberg et al., 1965, 1969; Rosenberg, 1973; Cleare and Hydes, 1980).

One reason for testing any potentially promising new group of antimicrobial agents is constituted by the alarming and rapidly increasing spread of various pathogens that are resistant to previously known clinically useful antimicrobial drugs. Such microbes include for example vancomycin-resistant enterococci (VRE) and methicillin-resistant Staphylococcus aureus (MRSA) that have become serious problems world-wide (Bozdogan et al., 2003; Centers for Disease Control and Prevention,
2002; Cetinkaya et al., 2000; Cunha, 2005; Hanaki et al., 2005; Hsueh et al., 2005; Weigelt et al., 2004). Thus, also from this point of view, antineoplastic and cytotoxic copper chelates and their ligands merit a thorough antimicrobial activity study.

I report here the characterization of the antimicrobial properties of pyridine-2-carboxaldehyde thiosemicarbazone and the acetate form of its 1:1 copper(II) chelate against a panel of nine different micro-organisms including bacteria, yeasts and one mold, as well as against some clinical isolates. The compounds studied are the ones whose antitumour properties have been most deeply investigated in the class of the thiosemicarbazones of $\alpha$ $N$-heterocyclic carboxaldehydes and their chelates. These compounds are interesting not only because of the reasons mentioned above but also because they inhibit ribonucleotide reductase, a rate-limiting enzyme of DNA synthesis (Saryan et al., 1979; Cory et al., 1994, 1995; Snyder, 1984), and are considered to be among the most promising inhibitors of this enzyme (Li et al., 2001).

The results now obtained indicate that both compounds have interesting antimicrobial properties.

\section{Experimental}

\section{Materials}

The compounds studied, pyridine-2-carboxaldehyde thiosemicarbazone (Hemmerich et al., 1958) and the acetate form of its 1:1 copper(II) chelate [2-formylpyridine thiosemicarbazonatocopper(II) acetate] (Antholine et al., 1976), were synthesized essentially according to the literature methods, and gave adequate elementary analyses for $\mathrm{C}, \mathrm{H}$, $\mathrm{N}$ and $\mathrm{S}$. The analysis results of the chelate are consistent with the composition $\left[\mathrm{Cu}^{2+}\left(\mathrm{C}_{7} \mathrm{H}_{7} \mathrm{~N}_{4} \mathrm{~S}\right)^{-}\right.$ $\left.\left(\mathrm{CH}_{3} \mathrm{COO}\right)^{-}\right]$. Bell and Theocharis (1987) have reported a dimeric structure for this complex.

The free ligand was dissolved in dimethyl sulfoxide (DMSO) for antimicrobial activity testing. The chelate did not dissolve completely in DMSO, and a DMSO suspension was therefore used.

The microbes studied included six bacterial species (Bacillus cereus, Escherichia coli, Pseudomonas aeruginosa, Staphylococcus aureus, Staphylococcus epidermidis and Streptococcus lactis), two yeasts (Candida albicans and Saccharomyces cerevisiae) as well as one mold (Aspergillus niger). Three clinical isolates [two Bacillus isolates from a Finnish clinical laboratory and one reference 
strain of B. cereus (NEQAS 7594/2006)] were also studied. Three slightly different paper disc agar diffusion methods were used in the antimicrobial activity studies performed.

\section{Method I}

Method I is a routine screening method that was used for a long time in my laboratory, and it was used in the early phase of the present study. In that method, all of the microbial species except for S. aureus and S. lactis were included in the test panel, and four concentrations of test substances were normally studied $(5,10,20$ and $40 \mathrm{mg} / \mathrm{ml})$. This method, the origins of the microbial strains used as well as the maintainance of the strains have been described previously (Pelttari et al., 2002), alongside with a description of the materials used. In brief, for testing of antimicrobial activities, colonies were taken from agar plates and grown aerobically (at 30 or $37^{\circ} \mathrm{C}$ ) in several $5 \mathrm{ml}$ aliquots of the appropriate liquid medium. Liquid cultures from over-night cultivations $(5 \mathrm{ml}$ each) were centrifuged, the pellets were washed, recentrifuged and resuspended (volume $400 \mu \mathrm{l}$ ), and $200 \mu \mathrm{l}$ of this suspension were inoculated onto each plate (diameter $14 \mathrm{~cm}$, approximately $50 \mathrm{ml}$ of agar). Paper discs (diameter $6 \mathrm{~mm}$ ) were put onto the plates, and $10 \mu \mathrm{l}$ of a test solution were pipetted onto each disc. For each concentration of each compound four discs were employed.

\section{Method II}

In Method II, all of the above-mentioned strains were used except for $A$. niger and S. epidermidis. Two further strains were also used, namely one Staphylococcus aureus and one Streptococcus lactis strain. The S. aureus strain was an ATCC strain (ATCC 51740) and was obtained from the HAMBI collection of the University of Helsinki. The S. lactis strain was an NCDO strain (NCDO 712) and was obtained through the HAMBI collection from Valio Laboratories (Helsinki, Finland). The S. aureus strain was cultivated at $37^{\circ} \mathrm{C}$ in Müller-Hinton broth or on Müller-Hinton agar, and the S. lactis strain at $30^{\circ} \mathrm{C}$ in a modified tryptone soy broth or on modified tryptone soy agar. The strains were maintained as previously described for the strains used in Method I (Pelttari et al., 2002). The Müller-Hinton broth used was prepared by dissolving $21 \mathrm{~g}$ of a commercially available powder (Difco product 275730, Becton
Dickinson Microbiology Systems, Sparks, MD, USA) in 11 of deionized water under heating and the Müller-Hinton agar by dissolving $38 \mathrm{~g}$ of a commercially available powder containing also the agar (Difco product 225250) in 11 of deionized water under heating. The modified tryptone soy broth was prepared by dissolving $30 \mathrm{~g}$ of a commercial tryptone soy broth powder (Ph.Eur/USP, product BK046HA, Biokar Diagnostics, Zac de Ther, Allonne, Beauvais, France) and $3 \mathrm{~g}$ of yeast extract (product 1.03753.0500, E. Merck, Darmstadt, Germany) in 11 of deionized water, and the corresponding agar was prepared similarly except that also $16 \mathrm{~g}$ of agar powder (Ph.Eur) were added per litre.

Method II is a modification of Method I. The maintainance as well as growth conditions of the microbes were the same as in Method I. For agar diffusion studies, however, liquid cultures were not grown but colonies of the microbes were taken directly from fresh cultures on agar plates and were suspended in $0.9 \%$ saline to yield a slightly opalesquent suspension (minimum 0.5 MacFarland, preferably more). This suspension was then spread manually on the plates with the aid of cotton swabs having a very large "head" at the end ("medical applicators", Applimed SA, ChâtelSaint-Denis, Switzerland and Dansu A/S, Stenlose, Denmark; sterilized by autoclaving in my laboratory). The swab was immersed in the suspension and its head was then lightly pressed against the inner wall of the tube to remove excess liquid. Great care was exercised in spreading the suspension onto the plates, in order to obtain a very homogenous plate. The rest of the method was similar to that of Method I. In connection with Method II, six concentrations of each sample were used. For each concentration of each compound, at least two discs were employed. Both methods were used for most of the strains for comparison purposes.

\section{Method III}

Method III was used in the case of clinical isolates of Bacillus sp. It was performed essentially according to Finnish national standards for antibiotic sensitivity testing in clinical microbiology (FiRe standard), and the exact protocol used in our studies has been published (Elo et al., 2007). In brief, microbes from fresh pure cultures were suspended in $0.9 \%$ saline to yield 0.5 MacFarland suspensions that were spread on Müller-Hinton 
plates (LabM, U. K.) on a rotary plater according to the Kirby-Bauer method. On each plate were put two filter paper discs of $6 \mathrm{~mm}$ diameter (sterilized by autoclaving). On one disc, $10 \mu \mathrm{l}$ of DMSO as solvent control, and on the other one, $10 \mu \mathrm{l}$ of a DMSO solution of pyridine-2-carboxaldehyde thiosemicarbazone or of a DMSO suspension of its copper(II) chelate were pipetted. The plates were incubated at $(35 \pm 2){ }^{\circ} \mathrm{C}$ for $20 \mathrm{~h}$, and the diameters of the inhibitory zones were measured. All tests were performed in triplicate.

\section{Results and Discussion}

The antimicrobial properties of pyridine-2-carboxaldehyde thiosemicarbazone (Fig. 1) as well as of the acetate form of its 1:1 copper(II) chelate [i.e., 2-formylpyridine thiosemicarbazonatocop-

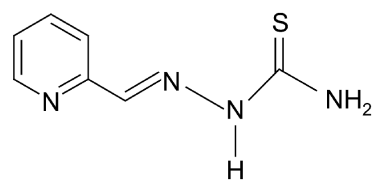

Fig. 1. Structure of the free ligand pyridine-2-carboxaldehyde thiosemicarbazone.
per(II) acetate] were studied using nine different micro-organisms, including six bacterial species (Bacillus cereus, Escherichia coli, Pseudomonas aeruginosa, Staphylococcus aureus, Staphylococcus epidermidis and Streptococcus lactis), two yeasts (Candida albicans and Saccharomyces cerevisiae) as well as one mold (Aspergillus niger). In addition, the compounds were tested against three clinical isolates of the genus Bacillus. The results obtained are shown in Tables I and II.

As is evident from the Tables, both the free ligand and the copper chelate had marked antimicrobial activity. The growth of each microbial strain studied was inhibited either by the free ligand or by its copper(II) chelate or by both.

In the case of B. cereus, tested by using Method I (Table I), the copper chelate seemed to have slight activity even at the lowest concentration studied, but its activity did not increase with concentration. The free ligand, however, had considerable dose-dependent activity and gave inhibitory zones large enough to make it a compound of potential practical interest, at least as a lead compound for the development of more active congeners, or even as such. The inhibitory zones were,

Table I. Results of the antimicrobial activity measurements that were performed according to Methods I and II.

\begin{tabular}{|c|c|c|c|c|c|}
\hline \multirow[t]{3}{*}{ Microbe } & \multirow{3}{*}{$\begin{array}{c}\text { Concentration } \\
\text { of test substance } \\
{[\mathrm{mg} / \mathrm{ml}]^{\mathrm{a}}}\end{array}$} & \multicolumn{4}{|c|}{ Mean diameter of inhibitory zone \pm standard deviation $[\mathrm{mm}]^{\mathrm{b}}$} \\
\hline & & \multicolumn{2}{|c|}{ Copper chelate ${ }^{c}$} & \multicolumn{2}{|c|}{ Free ligand ${ }^{\mathrm{d}}$} \\
\hline & & Method I & Method II & Method I & Method II \\
\hline \multirow[t]{4}{*}{ B. cereus } & 5 & $10 \pm 0$ & $\mathrm{ND}^{\mathrm{e}}$ & $6 \pm 0.5$ & ND \\
\hline & 10 & $10 \pm 0.8$ & ND & $6 \pm 0.5$ & ND \\
\hline & 20 & $11 \pm 1.0$ & ND & $17^{\mathrm{f}} \pm 1.0$ & ND \\
\hline & 40 & $11 \pm 0.8$ & ND & $16^{\mathrm{f}} \pm 1.0$ & ND \\
\hline \multirow[t]{6}{*}{ E. coli } & 1.25 & ND & $6 \pm 0$ & ND & $6 \pm 0.5$ \\
\hline & 2.5 & ND & $6 \pm 0$ & ND & $7 \pm 1.5$ \\
\hline & 5 & ND & $8 \pm 0.6$ & ND & $14 \pm 2.5$ \\
\hline & 10 & $11 \pm 0.5$ & $7 \pm 0.6$ & $25^{\mathrm{g}} \pm 1.0$ & $20 \pm 0.6$ \\
\hline & 20 & $9 \pm 0.8$ & $9 \pm 0.6$ & $21^{\mathrm{g}} \pm 1.0$ & $24 \pm 1.2$ \\
\hline & 40 & $9 \pm 1.0$ & $7 \pm 0.6$ & $26^{\mathrm{g}} \pm 1.0$ & $27 \pm 1.5$ \\
\hline \multirow[t]{6}{*}{ P. aeruginosa } & 1.25 & ND & $6 \pm 0$ & ND & $7 \pm 1.2$ \\
\hline & 2.5 & ND & $6 \pm 0$ & ND & $\begin{array}{c}8 \pm 0.3 / \\
14 \text { (outer zone } \\
\text { in one case) }\end{array}$ \\
\hline & 5 & $9 \pm 0.6$ & $6 \pm 0$ & $19 \pm 1.5$ & $\begin{array}{r}8 \pm 0.3 / \\
18 \pm 2.8^{\mathrm{h}}\end{array}$ \\
\hline & 10 & $7 \pm 0.6$ & $6 \pm 0$ & $\begin{array}{c}8 \text { (inner zone in } \\
\text { one case)/ } \\
18 \pm 1.2^{\mathrm{h}}\end{array}$ & $\begin{array}{l}13 \pm 2.6 / \\
24 \pm 4.2^{\mathrm{h}}\end{array}$ \\
\hline & 20 & $7 \pm 0$ & $6 \pm 0$ & $\begin{array}{l}13 \pm 1.0 / \\
22 \pm 1.0^{\mathrm{h}}\end{array}$ & $29 \pm 3.1^{\mathrm{i}}$ \\
\hline & 40 & $8 \pm 0.6$ & $6 \pm 0$ & $\begin{array}{l}19 \pm 0.5 / \\
25 \pm 0.6^{\mathrm{h}}\end{array}$ & $31 \pm 2.0^{\mathrm{i}}$ \\
\hline
\end{tabular}


Table I (continued).

\begin{tabular}{|c|c|c|c|c|c|}
\hline \multirow[t]{3}{*}{ Microbe } & \multirow{3}{*}{$\begin{array}{c}\text { Concentration } \\
\text { of test substance } \\
{[\mathrm{mg} / \mathrm{ml}]^{\mathrm{a}}}\end{array}$} & \multicolumn{4}{|c|}{ Mean diameter of inhibitory zone \pm standard deviation $[\mathrm{mm}]^{\mathrm{b}}$} \\
\hline & & \multicolumn{2}{|c|}{ Copper chelate ${ }^{\mathrm{c}}$} & \multicolumn{2}{|c|}{ Free ligand ${ }^{\mathrm{d}}$} \\
\hline & & Method I & Method II & Method I & Method II \\
\hline \multirow[t]{6}{*}{ S. aureus } & 1.25 & ND & $8 \pm 0.3$ & ND & $6 \pm 0$ \\
\hline & 2.5 & ND & $9 \pm 0$ & ND & $6 \pm 0.5$ \\
\hline & 5 & ND & $10 \pm 0.8$ & ND & $14 \pm 2.4$ \\
\hline & 10 & ND & $11 \pm 1.0$ & ND & $19 \pm 2.1$ \\
\hline & 20 & ND & $13 \pm 0.9$ & ND & $20 \pm 2.2$ \\
\hline & 40 & ND & $13 \pm 0.5$ & ND & $23 \pm 2.8$ \\
\hline \multirow[t]{4}{*}{ S. epidermidis } & 5 & $25 \pm 1.0$ & $\mathrm{ND}$ & $6 \pm 0$ & ND \\
\hline & 10 & $28 \pm 1.0$ & ND & $6 \pm 0.5$ & ND \\
\hline & 20 & $25 \pm 1.0$ & ND & $20 \pm 1.4^{\mathrm{f}}$ & ND \\
\hline & 40 & $28 \pm 1.0$ & ND & $21 \pm 1.6^{\mathrm{f}}$ & ND \\
\hline \multirow[t]{6}{*}{ S. lactis } & 1.25 & ND & $6 \pm 0$ & ND & $6 \pm 0$ \\
\hline & 2.5 & ND & $6 \pm 0$ & ND & $6 \pm 0$ \\
\hline & 5 & ND & $7 \pm 0.4$ & ND & $6 \pm 0$ \\
\hline & 10 & ND & $8 \pm 0$ & ND & $6 \pm 0$ \\
\hline & 20 & ND & $8 \pm 0.4$ & ND & $6 \pm 0$ \\
\hline & 40 & ND & $10 \pm 0.7$ & ND & $6 \pm 0$ \\
\hline \multirow[t]{6}{*}{ C. albicans } & 1.25 & ND & $6 \pm 0$ & ND & $6 \pm 0$ \\
\hline & 2.5 & ND & $6 \pm 0$ & ND & $6 \pm 0$ \\
\hline & 5 & $6 \pm 0$ & $6 \pm 0$ & $6 \pm 0$ & $6 \pm 0$ \\
\hline & 10 & $6 \pm 0$ & $6 \pm 0$ & $9 \pm 1.0$ & $6 \pm 0$ \\
\hline & 20 & $6 \pm 0$ & $6 \pm 0$ & $14 \pm 0.7$ & $9 \pm 0.6$ \\
\hline & 40 & $6 \pm 0$ & $6 \pm 0$ & $15 \pm 0.5$ & $13 \pm 1$ \\
\hline \multirow[t]{6}{*}{ S. cerevisiae } & 1.25 & $\mathrm{ND}$ & $6 \pm 0$ & ND & $6 \pm 0$ \\
\hline & 2.5 & ND & $9 \pm 0$ & ND & $6 \pm 0$ \\
\hline & 5 & PART $^{j}$ & $14 \pm 1.0 /$ & $6 \pm 0$ & $6 \pm 0$ \\
\hline & 10 & PART & $\begin{array}{l}22 \pm 4.5^{\mathrm{h}} \\
15 \pm 0.6 / \\
23 \pm 1.2^{\mathrm{h}}\end{array}$ & $6 \pm 0$ & $6 \pm 0$ \\
\hline & 20 & PART & $\begin{array}{l}18 \pm 2.1 / \\
27 \pm 2.5^{\mathrm{h}}\end{array}$ & $6 \pm 0$ & $6 \pm 0$ \\
\hline & 40 & PART & $\begin{array}{l}18 \pm 2.6 / \\
28 \pm 1.7^{\mathrm{h}}\end{array}$ & $6 \pm 0$ & $6 \pm 0$ \\
\hline \multirow{4}{*}{ A. niger } & 5 & $6 \pm 0$ & ND & $6 \pm 0^{\mathrm{k}}$ & ND \\
\hline & 10 & $6 \pm 0$ & ND & $16 \pm 1.7$ & ND \\
\hline & 20 & $6 \pm 0$ & ND & $23 \pm 1.0$ & ND \\
\hline & 40 & $6 \pm 0$ & ND & $23 \pm 1.3$ & ND \\
\hline
\end{tabular}

a Concentration of test substance in DMSO. $10 \mu \mathrm{l}$ of this solution or suspension were pipetted onto each paper disc.

$\mathrm{b}$ Diameter of filter paper disc $=6 \mathrm{~mm}$. The diameters given include the disc diameter. The solvent (DMSO) alone never gave any inhibitory zone.

c Suspension.

d Solution.

e ND, not determined.

f Partial inhibition.

$\mathrm{g}$ The borders of the inhibitory zones were not sharp.

$\mathrm{h}$ Two inhibitory zones (usually a clear inner one and a more diffuse outer one).

i Outer zone. The diameter of the inner zone could not be reliably determined.

j PART, partial inhibition was distinctly observed but definitive determination of the diameter of the inhibitory zone was impossible.

k Difficult to determine, possibly some inhibition.

however, diffuse and appeared to consist of an inner zone and a less clear outer zone, suggesting partial growth in the peripheral part of the zone.
The compounds were tested also against two clinical isolates of the genus Bacillus obtained from patients in Finland as well as against one 
Table II. Results of the measurements of antibacterial activity against clinical isolates of Bacillus sp.

\begin{tabular}{|c|c|c|c|}
\hline \multirow[t]{2}{*}{ Compound $^{\mathrm{a}}$} & \multicolumn{3}{|c|}{$\begin{array}{c}\text { Mean diameter of inhibitory } \\
\text { zone } \pm \text { standard deviation }[\mathrm{mm}]^{\mathrm{b}}\end{array}$} \\
\hline & $\begin{array}{c}\text { B. cereus } \\
\text { (NEQAS } \\
7594 / 2006)\end{array}$ & $\begin{array}{l}\text { Bacillus sp., } \\
\text { clinical } \\
\text { isolate } 1\end{array}$ & $\begin{array}{l}\text { Bacillus sp., } \\
\text { clinical } \\
\text { isolate } 2\end{array}$ \\
\hline $\begin{array}{l}\text { Free ligand } \\
\text { Copper chelate } \\
\text { DMSO (solvent }^{\text {D }} \\
\text { control) }\end{array}$ & $\begin{array}{l}14 \pm 0.6 \\
13 \pm 0 \\
6 \pm 0\end{array}$ & $\begin{aligned} 23 & \pm 0.6 \\
18 & \pm 0.6 \\
6 & \pm 0\end{aligned}$ & $\begin{aligned} 25 & \pm 0.6 \\
18 & \pm 0.6 \\
6 & \pm 0\end{aligned}$ \\
\hline \multicolumn{4}{|c|}{$\begin{array}{l}\text { The concentration of each test substance in DMSO } \\
\text { was } 40 \mathrm{mg} / \mathrm{ml} .10 \mu \mathrm{l} \text { of this solution or suspension were } \\
\text { pipetted onto each paper disc. } \\
\text { b Diameter of filter paper disc }=6 \mathrm{~mm} \text {. The diameters } \\
\text { given include the disc diameter. } \\
\text { c Solution. } \\
\text { d Suspension. }\end{array}$} \\
\hline
\end{tabular}

clinical reference strain (B. cereus NEQAS 7594/ 2006). Those results are shown in Table II. All three strains were inhibited by both the copper chelate and the free ligand, the two clinical isolates being inhibited remarkably well and clearly more potent than the reference strain. The free ligand was apparently more effective than the chelate.

In the case of E. coli, tested by using both Method I and Method II, the chelate had almost no activity, while the free ligand gave large inhibitory zones that, however, were not totally clear in the case of Method I. So, partial growth possibly occurred also in this case. In any case, the high activity of the free ligand is of interest. Whether the apparent diffuse growth inside the inhibitory zones is an indication of phenotypic heterogeneity or not remains to be studied. Another possibility is that the compound has bacteriostatic activity that is marked but not complete, but does not have bactericidal activity.

In the case of $P$. aeruginosa, the free ligand clearly and without any doubt gave in most cases two inhibitory zones, namely a clear inner one (obviously no growth) and a more diffuse outer one (obviously partial inhibition and partial growth). Even the inner inhibitory zone was that large that practical applications are of interest. This result is especially interesting since in a large screening program undergoing in my laboratory, very few compounds have been found that are highly active against $P$. aeruginosa, while a considerable number of compounds active against the other test organisms now employed have been found (Elo et al.,
2007; Pelttari et al., 2002, 2007a, 2007b; unpublished results). In contrast to the free ligand, the copper chelate had either minimal (Method I) or no (Method II) activity against $P$. aeruginosa.

In the case of the important opportunistic pathogen S. aureus, both pyridine-2-carboxaldehyde thiosemicarbazone and the chelate clearly had activity, the free ligand being far more active than the metal chelate. It is noteworthy that the ligand had marked activity even at fairly low concentrations. Unexpectedly, the results obtained on S. epidermidis differ drastically from those obtained for S. aureus. Thus, the copper chelate was highly active against $S$. epidermidis even at the lowest concentration tested. The free ligand was less active (albeit it had potent activity) and did not display essentially any activity at the lowest concentrations tested. In the case of the ligand, the inhibitory zones were unclear, suggesting partial growth.

In contrast to the other bacteria studied, S. lactis was very weakly inhibited by the chelate and not detectably inhibited by the free ligand. The reasons for this difference remain to be studied.

In the case of the pathogenic yeast $C$. albicans, the copper chelate was totally inactive, as determined by Methods I and II. The free ligand, however, had moderate activity. Possibly, topical applications against this pathogen might come into question. The other yeast studied, S. cerevisiae, was in contrast not detectably inhibited by the free ligand even at the highest concentrations tested but was markedly inhibited by the copper chelate. When Method II was employed, the chelate produced two inhibitory zones (a clear inner one and a diffuse outer one), just as the free ligand did in the case of some bacteria.

The mold $A$. niger is an opportunistic pathogen of rapidly increasing importance because immunocompromised patients (such as AIDS patients and patients with transplanted organs who are on immunosuppressive medication) are susceptible to it. Thus, every compound with marked activity against it is of potential value. The free ligand now studied had marked activity against this microbe, being thus of interest as a lead compound for the development of anti-mold drugs. The copper chelate, instead, displayed no activity.

The formation of two distinctly discernable inhibitory zones in many cases is interesting and may suggest that at low concentrations, the free ligand and the chelate are in these cases only bacteriostatic or fungistatic (respectively), but that at 
certain concentrations (at certain intracellular concentrations within the microbes?), the compounds become bactericidal or fungicidal, respectively.

It must be pointed out that the 'intrinsic' antimicrobial activity of the copper chelate may actually be higher than suggested by the present results, since its solubility in DMSO was low and a suspension had to be used. Whether higher activity could be obtained e.g. by pretreating the microbes with a copper(II) salt and then administering the free ligand remains to be studied. Such a prodecure (or simultaneous administration of the ligand and a copper salt) could possibly be used even in vivo.

An interesting question is, whether the antibacterial, antifungal and antineoplastic activities of the free ligand and of the copper chelate all have one and the same mechanism of action or not. The role of copper (and other metal) ions in the antibacterial and antifungal activities of the free ligand is interesting but outside the scope of the present study. It is also the question, whether the chelate reacts intracellularly, releasing the free ligand, or not and if so, what happens to the copper(II) ion released. These questions are worth to be studied further, since they are of great interest as concerns the development of further active agents for possible practical use. One further question of great interest is whether the antibacterial and antifungal

Agrawal K. C. and Sartorelli A.C. (1975), $\alpha-(N)$-Heterocyclic carboxaldehyde thiosemicarbazones. In: Handbuch der Experimentellen Pharmakologie - Handbook of Experimental Pharmacology, Vol. 38/2 (Sartorelli A. C. and Johns D. G., eds.) Springer-Verlag, Berlin, pp. 793-807.

Antholine W. E., Knight J. M., and Petering D. H. (1976), Inhibition of tumor cell transplantability by iron and copper complexes of 5-substituted 2-formylpyridine thiosemicarbazones. J. Med. Chem. 19, 339-341.

Bell C. F. and Theocharis C. R. (1987), Structure of the antitumor agent di- $\mu$-acetato-(O)-bis[(2-pyridinecarbaldehyde thiosemicarbazonato)copper(II)]. Acta Cryst. C 43, 26-29.

Bozdogan B., Esel D., Whitener C., Browne F. A., and Appelbaum P. C. (2003), Antibacterial susceptibility of a vancomycin-resistant Staphylococcus aureus strain isolated at the Hershey Medical Center. J. Antimicr. Chemother. 52, 864-868.

Brockman R. W., Thomson J. R., Bell M. J., and Skipper H. E. (1956), Observations on the antileukemic activity of pyridine-2-carboxaldehyde thiosemicarbazone and thiocarbohydrazone. Cancer Res. 16, 167-170. activity of the present compounds is due to their well-known ability to inhibit ribonucleotide reductase or not (Saryan et al., 1979).

One further interesting question is, what causes the inter-species differences now observed. For example, what makes $E$. coli highly sensitive to the free ligand, the chelate being far less active, while S. epidermidis is sensitive to both ones and especially sensitive to the chelate? Possible differences in the cellular uptake of the compounds might be one reason, and differences in intracellular concentrations of copper or other metals is another possibility. Even different compositions of the culture media may play a role.

The present free ligand, pyridine-2-carboxaldehyde thiosemicarbazone, and its derivatives and analogues are worth to be further studied for their antimicrobial activity, since in the present study, distinct antimicrobial activity was found. Since some thiosemicarbazones of $\alpha-N$-heterocyclic carboxaldehydes have been or are subject to clinical trials on humans or are entering such trials because of their antineoplastic properties (Petering, 1980; Shao et al., 2006; Feun et al., 2002; Murren et $a l ., 2003)$, their route to clinical trials and practical clinical use also as antimicrobials might be much more straightforward than that of substances or substance classes, whose toxicity in humans is wholly unexplored.
Centers for Disease Control and Prevention (2002), Staphylococcus aureus resistant to vancomycin Unites States, 2002. Morb. Mortal. Wkly. Rep. 51, $565-567$.

Cetinkaya Y., Falk P., and Mayhall C. G. (2000), Vancomycin-resistant enterococci. Clin. Microbiol. Rev. 13, 686-707.

Chattopadhyay S. K., Hossain M., Ghosh S., and Guha A. (1990), Ligational behavior of two biologically active nitrogen-sulfur donors towards cobalt(III), iron(III), iron(II) and rhodium(III). Transition Met. Chem. 15, 473-477.

Cleare M. J. and Hydes P. C. (1980), Antitumor properties of metal complexes. In: Metal Ions in Biological Systems, Vol. 11 (Sigel H., ed.). Marcel Dekker, Inc., New York, pp. 1-62.

Cory J. G., Cory A. H., Rappa G., Lorico A., Liu M. C., Lin T. S., and Sartorelli A. C. (1994), Inhibitors of ribonucleotide reductase. Comparative effects of amino- and hydroxy-substituted pyridine-2-carboxaldehyde thiosemicarbazones. Biochem. Pharmacol. 48, $335-344$.

Cory J. G., Cory A. H., Rappa G., Lorico A., Liu M. C., Lin T. S., and Sartorelli A. C. (1995), Structure-func- 
tion relationships for a new series of pyridine-2-carboxaldehyde thiosemicarbazones on ribonucleotide reductase activity and tumor cell growth in culture and in vivo. Adv. Enz. Regul. 35, 55-68.

Cunha B. A. (2005), Methicillin-resistant Staphylococcus aureus: clinical manifestations and antimicrobial therapy. Clin. Microbiol. Infect. 11, 33-34.

Elo H. (1987a), Reaction of the antiproliferative and antineoplastic agent trans-bis(salicylaldoximato)copper(II) and related chelates with glutathione and cysteine. Correlation between reactivity and biological activity. Inorg. Chim. Acta 136, L33-L35.

Elo H. (1987b), An antiproliferative salicylaldoximato type copper(II) chelate as an enhancer of the cytotoxicity of murine spleen cells to tumor cells in vitro. Cancer Lett. 36, 333-339.

Elo H. (2004a), Uniform potent activity of the antiproliferative metal chelate trans-bis(resorcylaldoximato)copper(II) against a large panel of human tumor cell lines in vitro. Chemotherapy 50, 229-233.

Elo H. (2004b), The antiproliferative agents trans-bis(resorcylaldoximato)copper(II) and trans-bis(2,3,4-trihydroxybenzaldoximato)copper(II) and cytopathic effects of HIV. Z. Naturforsch. 59c, 609-611.

Elo H. O. and Lumme P. O. (1985), Antitumor activity of trans-bis(salicylaldoximato)copper(II): a novel antiproliferative metal complex. Cancer Treat. Rep. 69, $1021-1022$.

Elo H. and Lumme P. (1986), Antiproliferative activity of derivatives of trans-bis(salicylaldoximato)copper(II) in vitro. Some in vivo properties of the parent compound. Z. Naturforsch. 41c, 951-955.

Elo H. and Lumme P. (1987), Trans-bis(salicylaldoximato)copper(II) and its derivatives as antiproliferative and antineoplastic agents: a review. Inorg. Chim. Acta 136, $149-153$.

Elo H. and Sunila I. (1987), Unusual organ distribution of chelated copper in rats. Naturwissenschaften $\mathbf{7 4}$, $245-246$.

Elo H., Sunila I., and Lumme P. (1987), Studies on the acute toxicity of the antineoplastic metal chelate trans-bis(salicylaldoximato)copper(II) in rats. Inorg. Chim. Acta 136, 61-63.

Elo H., Matikainen J., and Pelttari E. (2007), Potent activity of the lichen antibiotic (+)-usnic acid against clinical isolates of vancomycin-resistant enterococci and methicillin-resistant Staphylococcus aureus. Naturwissenschaften 94, 465-468.

Feun L., Modiano M., King L., Mao J., Marini A., Savaraj N., Plezia P., Almassian B., Colacino E., Fischer J., and MacDonald S. (2002), Phase I and pharmacokinetic study of 3-aminopyridine-2-carboxaldehyde thiosemicarbazone (3-AP) using a single intravenous dose schedule. Cancer Chemother. Pharmacol. 50, 223-229.

Hanaki H., Yamaguchi Y., Yanagisawa C., Uehara K., Matsui H., Yamaguchi Y., Hososaka Y., Barada K., Sakai F., Itabashi Y., Ikeda S., Atsuda K., Tanaka H., Inamatsu T., Nagayama A., and Sunakawa K. (2005), Investigation of beta-lactam antibiotic-induced vancomycin-resistant MRSA (BIVR). J. Infect. Chemother. 11, 104-106.
Hemmerich P., Prijs B., and Erlenmeyer H. (1958), Pyridyl-1,3,4-thiadiazole; eine neue Variante der Thiadiazol-Synthese. Helv. Chim. Acta 40, 2058-2065.

Hochman H. I., Agrawal K. C., and Sartorelli A. C. (1972a), Biochemical studies of the effects of 1 -formylisoquinoline thiosemicarbazone (IQ-1) in Escherichia coli B. Biochem. Pharmacol. 21, 3213-3221.

Hochman H. I., Agrawal K. C., and Sartorelli A. C. (1972b), Localization in Escherichia coli B of two enzymic sites of action by 1 -formylisoquinoline thiosemicarbazone (IQ-1) on ribonucleic acid biosynthetic pathways. Biochem. Pharmacol. 21, 3223-3233.

Hsueh P.-R., Chen W.-H., Teng L.-J., and Luh K.-T. (2005), Nosocomial infections due to methicillin-resistant Staphylococcus aureus and vancomycin-resistant enterococci at a university hospital in Taiwan from 1991 to 2003; resistance trends, antibiotic usage and in vitro activities of newer antimicrobial agents. Int. J. Antimicr. Agents 26, 43-49.

Li J., Zheng L. M., King I., Doyle T. W., and Chen S. H. (2001), Syntheses and antitumor activities of potent inhibitors of ribonucleotide reductase: 3-amino-4methylpyridine-2-carboxaldehyde-thiosemicarbazone (3-AMP), 3-amino-pyridine-2-carboxaldehyde-thiosemicarbazone (3-AP) and its water-soluble prodrugs. Curr. Med. Chem. 8, 121-133.

Maiti A., Guha A. K., and Ghosh S. (1988), Ligational behavior of two biologically active N-S donors toward oxovanadium(IV) ion and potentiation of their antibacterial activities by chelation to metal ions. Part III. J. Inorg. Biochem. 33, 57-65.

Murren J., Modiano M., Clairmont C., Lambert P., Savaraj N., Doyle T., and Sznol M. (2003), Phase I and pharmacokinetic study of triapine, a potent ribonucleotide reductase inhibitor, administered daily for five days in patients with advanced solid tumors. Clin. Cancer Res. 9, 4092-4100.

Pelttari E., Matikainen J., and Elo H. (2002), Antimicrobial activity of the marine alkaloids haminol and pulo'upone and related compounds. Z. Naturforsch. 57c, $548-552$.

Pelttari E., Karhumäki E., Langshaw J., Peräkylä H., and Elo H. (2007a), Antimicrobial properties of substituted salicylaldehydes and related compounds. Z. Naturforsch. 62c, 487-497.

Pelttari E., Karhumäki E., Langshaw J., and Elo H. (2007b), Carbohydrazones of substituted salicylaldehydes as potential lead compounds for the development of narrow-spectrum antimicrobials. Z. Naturforsch. 62c, 483-486.

Petering D. H. (1980), Carcinostatic copper complexes. In: Metal Ions in Biological Systems, Vol. 11 (Sigel H., ed.). Marcel Dekker, Inc., New York, pp. 197-229.

Rosenberg B. (1973), Platinum coordination complexes in cancer chemotherapy. Naturwissenschaften 60, 399-406.

Rosenberg B. (1980), Clinical aspects of platinum anticancer drugs. In: Metal Ions in Biological Systems, Vol. 11 (Sigel H., ed.). Marcel Dekker, Inc., New York, pp. 127-196.

Rosenberg B., Van Camp L., and Krigas T. (1965), Inhibition of cell division in Escherichia coli by electrolysis products from a platinum electrode. Nature 205, $698-699$. 
Rosenberg B., Van Camp L., Trosko J. E., and Mansour V. H. (1969), Platinum compounds: a new class of potent antitumour agents. Nature 222, 385-386.

Saryan L. A., Ankel E., Krishnamurti C., and Petering D. H. (1979), Comparative cytotoxic and biochemical effects of ligands and metal complexes of $\alpha-N$-heterocyclic carboxaldehyde thiosemicarbazones. J. Med. Chem. 22, 1218-1221.

Shao J., Zhou B., Chu B., and Yen Y. (2006), Ribonucleotide reductase inhibitors and future drug design. Curr. Cancer Drug Targets 6, 409-431.
Snyder R. D. (1984), Inhibitors of ribonucleotide reductase alter DNA repair in human fibroblasts through specific depletion of purine deoxynucleotide triphosphatases. Cell Biol. Toxicol. 1, 81-94.

Weigelt J., Kaafarani H. M. A., Itani K. M. F., and Swanson R. N. (2004), Linezolid eradicates MRSA better than vancomycin from surgical-site infections. Am. J. Surg. 188, 760-766. 